\title{
Apple Scab Disease Severity in the Sais Region of Morocco and its Sensitivity to Three Commercial Fungicides
}

\author{
Rachid LAHLALI ${ }^{1 *}$, Alieu MOININA ${ }^{1}$, Said EZRARI ${ }^{1,2}$, \\ Dustin MACLEAN ${ }^{3}$, Mohammed BOULIF ${ }^{1}$ \\ ${ }^{1}$ Ecole Nationale d'Agriculture de Meknès, Department of Crop Protection, Phytopathology Unit, BP/S 40, Meknès 50001, Morocco; \\ rlablali@enameknes.ac.ma (*correspondingauthor); malieu@enameknes.ac.ma; mboulif@enameknes.ac.ma \\ ${ }^{2}$ Sidi Mohamed Ben Abdellah University, Laboratory of Functional Ecology and Environment, PO Box 2202, Route d'Imouzzer, Fez, \\ Morocco; said.ezrari@usmba.ac.ma \\ ${ }^{3}$ University of Guelph, Department of Plant Agriculture, N1G2W1, Ontario, Canada; dmacle02@uoguelph.ca
}

\begin{abstract}
Apple scab, Venturia inaequalis (Cooke) G. Winter, results in numerous fungicide applications in the Sais region of Morocco. We conducted the study to determine the susceptibility of cultivars through field survey and to evaluate the sensitivity of $V$. inaequalis to three fungicides using both in vitro and in vivo methods. We surveyed 100 apple orchards and collected two samples. Disease survey showed that the cultivars were highly susceptible to apple scab (grand mean of leaf scab: Golden Delicious, 40.31\%; Starking Delicious, 20.45\%; and Gala, 18.92\%). Results underlined no significant differences between isolates in term of inhibition rate of mycelial growth and averaged disease severity. However, both treatment and concentration were statistically significant. $\mathrm{EC}_{50}$ values ranged from $2.33 \mu \mathrm{g} / \mathrm{ml}$ to $7.40 \mu \mathrm{g} / \mathrm{ml}$ and resistance factor (RF) values of $0.55,1.02$ and 1.79 were obtained for difenoconazole, trifloxystrobin and thiophanate-methyl, respectively. In vivo tests at a concentration of $10 \mu \mathrm{g} / \mathrm{ml}$ on the isolate ViIF using a curative method showed a high efficacy of trifloxystrobin (96.38\%), and low efficacy of thiophanate-methyl (29.65\%) and difenoconazole (24.62\%). V. inaequalis was most sensitive to trifloxystrobin followed by difenoconazole and thiophanate-methyl, respectively. From this work, it was recommended testing more isolates and contact fungicides in order to develop a baseline sensitivity of the pathogen population against commonly used fungicides to treat the disease, as continued usage over time and the introduction of new fungal races may result in a decrease in fungicide efficacy.
\end{abstract}

Keywords: apple cultivars; efficacy; Sais region; sensitivity; susceptibility; Venturia inaequalis

\section{Introduction}

Apple scab caused by Venturia inaequalis (Cooke) G. Winter, is among the most prevalent and economically major diseases in commercial apple orchards in regions with temperate climates worldwide ( MacHardy et al., 2001; Belfanti et al., 2004; Khajuria et al., 2012; Khajuria et al., 2018). The pathogen causes lesions that have a green-olive to velvety-brown coloration when it develops on the leaves and fruits. The lesions become covered with fungal mycelium and spores which is what gives an olive-darkgreen colour to the spots. These spots reduce photosynthetic activity and cause young leaf drop (Turechek, 2004). The development of apple scab is influenced by the temperature, the duration of the wetness of leaf, susceptibility of the plant to infection and vegetative growth stage (Belete and Boyraz, 2017). Apple scab may result in losses of up to $70 \%$ of the production value if left unchecked, as scabbed fruit are visually unappealing and unfit for sale (Belete and Boyraz, 2017; MacHardy, 2000).

Out of about twenty cultivars of apples grown in Morocco, 'Golden Delicious' occupies up to $50 \%$ of the surface area, followed by 'Starking Delicious' (14\%) and about 5\% of 'Gala' cultivar (MADRPM, 2014). Management of apple scab disease is expensive due to the high number of fungicide applications (12 to 20) (Oukabli, 2004; Moinina et al., 2018). In order to prevent the development of fungicide resistance in the pathogen population, a farmer needs to reduce fungicide sprays per season and alternate fungicides with different modes of action (MoA). These are key strategies to prevent the development of fungicide resistance in the pathogen population (Bowen et al., 2011). In Morocco, apple farmers 
250

have over 15 approved active ingredients for apple scab disease control (ONSSA, 2017). The three classes of systemic fungicides most widely used are methyl benzimidazole carbamates (MBC), demethylation inhibitors (DMIs) and quinone outside inhibitors (QoI). The overuse of certain fungicides has led to consumer concerns over their safety, including possible negative health effects. Fungicide application should usually start during the winter season, with copper-based contact fungicides being applied to protect against pathogen infection. In the early spring, when bud swelling and fruit set occur, a second preventive application should be done (Oukabli, 2004). Despite recommendations to apply fungicides early as a preventive measure, the use of fungicides later in the growing season when symptoms have already appeared has increased drastically.

The MoA of each fungicide group may differ from one another depending on its chemical class. MBC fungicides (e.g. thiophanate-methyl) prevent nuclear division by blocking the polymerization of tubulin that affects mitosis (Zhou et al., 2016). The fungicidal activity of DMIs is due to an inhibition of fungal synthesis of cytochrome P-450(CYP) -enzyme ergosterol (Fishel, 2005) with high levels of protective and curative efficacy against $V$. inaequalis (Villani et al., 2015). Trifloxystrobin inhibits spore germination and blocks electron transfer at the site of quinol oxidation (the Qo site) in the cytochrome bcl enzyme complex in the respiratory chain of fungal mitochondria (Köller et al., 2004; Bolton et al., 2013). A common active ingredient of strobilurin fungicides used in apple production is trifloxystrobin (Chapman et al., 2011).

The sensitivity of $V$. inaequalis to fungicides used in controlling apple scab has not been investigated in Morocco. Investigating the sensitivity of pathogens to fungicides is of great importance for crop protection. Furthermore, knowledge of sensitivity parameters will help prevent resistance of $V$. inaequalis to commonly used fungicide groups from occurring. Therefore, the specific objectives of our study were: (i) to determine the difference in the susceptibility of three popular cultivars through field survey, (ii) to evaluate the sensitivity of $V$. inaequalis to difenoconazole, thiophanate-methyl and trifloxystrobin in Ifrane, the apple producing province in the Sais region of Morocco, and (iii) to determine the severity of apple scab on detached leaves before and after fungicide treatments under in vivo conditions.

\section{Materials and Methods}

\section{Quantification of disease incidence and severity of apple scab in the field}

A total of 100 commercial apple orchards were surveyed during the fruit set stage in spring 2018 in the seven districts: 8 from Ain Leuh, 13 from Ait Naamane, 23 from Ait Sbaa, 8 Dayat Aoua, 24 from Laanoucer, 11 from Sidi El Makhfi and 13 from Tigrigra. We assessed the severity of apple scab by comparing sampled leaves to the standard scales. To do this, trees were keenly observed at random from each orchard. Disease incidence and severity were assessed on apple trees and leaves (Fig. 1A) with visible symptoms respectively. Disease incidence, the proportion of infected trees with at least one lesion on a leaf, was calculated:

$\mathrm{P}=\mathrm{n} / \mathrm{N} \times 100$

$(\mathrm{P}$ - Disease incidence expressed in percentage, $\mathrm{n}$ number of attacked trees, $\mathrm{N}$ - total number of investigated trees). The disease severity was scored as percentage plant leaf area infected with scab according to a scale of 0 to 7 (Croxall et al., 1952).

\section{Sample collection and culturing of two isolates of Venturia inaequalis \\ We collected two samples of apple leaves with} symptoms of $V$. inaequalis, one from a commercial orchard and the other from untreated apple trees. The commercial orchard sampled was located in Ifrane province $\left(33^{\circ} 24^{\prime}\right.$ $\left.52.35^{\prime \prime} \mathrm{N}, 5^{\circ} 17^{\prime} 30.84^{\prime \prime} \mathrm{W}\right)$ and non-commercial apple trees, in the National School of Agriculture of Meknes (33 50' $34.70^{\prime \prime N}, 5^{\circ} 28^{\prime} 35.22^{\prime \prime W}$ ). Apple leaves (Fig. 1A) with visible symptoms of $V$. inaequalis were packed in bags and kept at $4{ }^{\circ} \mathrm{C}$ for $24 \mathrm{~h}$ in the laboratory before beginning isolation of the pathogen.

In order to obtain isolates, we prepared potato dextrose agar medium (PDA) by peeling and boiling $250 \mathrm{~g}$ of potato tubers. After boiling, $700 \mathrm{ml}$ of the liquid was filtered and complemented with autoclaved distilled water to obtain one litre of solution. Thereafter, $15 \mathrm{~g}$ of anhydrous glucose and $20 \mathrm{~g}$ of agar was added to the solution. The solution underwent magnetic agitation on a hot plate and was autoclaved at $121^{\circ} \mathrm{C}$ for $20 \mathrm{~min}$. At room temperature, the antibiotics chloramphenicol $(50 \mu \mathrm{g} / \mathrm{ml})$ and acetic acid (2 $\mathrm{ml} / \mathrm{l}$ ) were added to the PDA medium so that the two isolates would not be contaminated.

Isolation of $V$. inaequalis was performed in aseptic conditions under the laminar flow cabinet, which had been previously disinfected. To do this, we cut the leaves showing visible symptoms of $V$. inaequalis into pieces with sterilized scissors. Two leaf pieces were then dipped in $70 \%$ ethanol for $30 \mathrm{sec}$ and then rinsed three times with autoclaved distilled water. Two leaf pieces were deposited at the opposite ends of a Petri dish containing PDA and kept at $23-25^{\circ} \mathrm{C}$. The growth of $V$. inaequalis obtained after 7 days of inoculation was then sub-cultured to get pure ones.

\section{Choice offungicides}

In addition to protective fungicides, apple farmers in Morocco rely on three classes of systemic fungicides, namely, methyl benzimidazole carbamate (MBC) fungicides, demethylation inhibitors (DMIs) and the quinone-outside inhibitors (QoI). The three most widely used systemic fungicides that belong to these classes are thiophanatemethyl, difenoconazole and trifloxystrobin, respectively (Moinina et al., 2018). Precisely, we used the three aforementioned active ingredients. The tested concentrations for each of the active ingredients were 0.05 , $0.5,1.0,5.0$ and $10.0 \mu \mathrm{g} / \mathrm{ml}$ for both in vitro and in vivo tests. The sensitivity of $V$. inaequalis mycelial growth to these fungicides at recommended rates were evaluated on two isolates, one collected from a commercial apple orchard (ViIF) and the other from untreated apple trees (ViEN). 
Determination of half-maximal effective concentration $\left(E C_{50}\right)$

The dishes were incubated at $24-25^{\circ} \mathrm{C}$ and the diameter of the resulting mycelial cultures was measured after 12 days. We repeated the experiment twice over in four replicates for each combination fungicide-concentration. In order to assess the sensitivity level of the tested isolates of $V$. inaequalis, radial mycelial growth $(\mathrm{mm})$ was recorded with the aid of a digital Vernier Caliper for each dish when the uncontaminated controls fully covered the Petri dish. The percent fungal growth inhibition was calculated according to Pandey et al. (1982):

Inhibition rate $(\%)=[(a-b) / a] \times 100$

where: a-growth in the control; b-growth in the sample.

For each isolate, linear regression analysis was conducted using percent inhibition of colony growth and concentration for the respective fungicides to determine the value of the effective concentration that inhibited isolate growth by $50 \%\left(\mathrm{EC}_{50}\right)$.

In vivo test of fungicide efficacy against $V$. inaequalis on detached leaves

We collected young apple leaves of 'Golden Delicious' cultivar with no visible symptoms of disease at the experimental site of the National School of Agriculture of Meknes. The protocol of pathogenicity by Nicholson $e t$ al.(1973) for testing of $V$. inaequalis by detached leaf assay was carefully implemented.

The experiment contained two treatments, looking at both the preventive and curative properties of the fungicides examined. For both approaches, detached leaves were submerged immediately in water. Thereafter, the leaves were gently rubbed to remove leaf hairs and debris and rinsed under running tap water for $15 \mathrm{~min}$. The petiole closest to the leaf base was cut at an angle to allow maximum vascular contact with water in the Petri dish. The leaves were then rinsed three times with sterile water. The leaf was then placed adaxial side up in the Petri dish to ensure contact of the cut petiole with the water agar (1.2\%).

For the preventive treatment, we first dipped the leaves in autoclaved distilled water amended with fungicide at a tested concentration for about two minutes. The treated leaves were then placed in Petri dishes with water agar medium for roughly two hours and allowed to dry before being inoculated with a conidial suspension of $V$. inaequalis.
For the curative treatment, the leaf was placed adaxial side up in the Petri dish to ensure contact between the cut petiole and the water agar. The upper leaf surface was kept dry in Petri dishes and placed in a laminar flow hood before dropping conidial suspension. Two hours later, a specific concentration of each fungicide was sprayed on each leaf in a Petri dish. $50 \mu \mathrm{L}$ of conidial suspension $\left(1 \times 10^{5}\right.$ conidia $/ \mathrm{ml}$ ) was dropped on the adaxial surface of each leaf for both treatments. There was no fungicide application applied to the leaf surface of the control. Two replicates each containing two apple leaves per Petri dish was made for each concentration tested. Petri dishes were then sealed and stored under bright fluorescent light with $16 \mathrm{~h}$ light at $20^{\circ} \mathrm{C}$ in a growth chamber. For both treatments, there were two experiments over time in four replicates (four leaves for each fungicide concentration).

Disease severity was determined 28 days after inoculation when the control was almost completely infected with $V$. inaequalis, by visually assessing the percentages of leaf area infected. The percentage of disease development of the leaves was rated on a 1-7 scale developed by Croxall et al.(1952) where $1=0 \%<$ percentage of scabbed leaf surface $(S)<1 \% ; 2=1 \%<S<5 \% ; 3=5 \%<S$ $<10 \% ; 4=10<S<25 \% ; 5=25 \%<S<50 \% ; 6=50 \%<S$ $<75 \% ; 7=75 \%<S$. The fungicide efficacy was calculated using Abbott's formula (Abbott, 1925),

Efficacy $(\%)=(X-Y) / X \times 100$

Where $\mathrm{X}$ is the disease severity of the control and $\mathrm{Y}$ is the disease severity of the treatment.

\section{Statistical analysis}

The linear regression equation ( $\mathrm{Y}=\%$ inhibition; $\mathrm{X}=$ concentrations) and the $\mathrm{EC}_{50}$ value was derived from the line of best-fit. The resistance factor (RF) for each isolate was calculated as the ratio between the $\mathrm{EC}_{50}$ value of the fungicide treated commercial orchard sample and the $\mathrm{EC}_{50}$ value of the untreated apple tree sample (Kunz et al., 1997). Analysis of variance (ANOVA) was used to determine the effects of fungicides and concentrations on the isolate and was carried out for both the in vitro and in vivo methods, and specific differences of disease severity were identified with Duncan's multiple range test using SPSS statistical analysis software (Version 20.0). Student test with twosample assuming unequal variances with alpha value at 0.05 were performed for field survey.

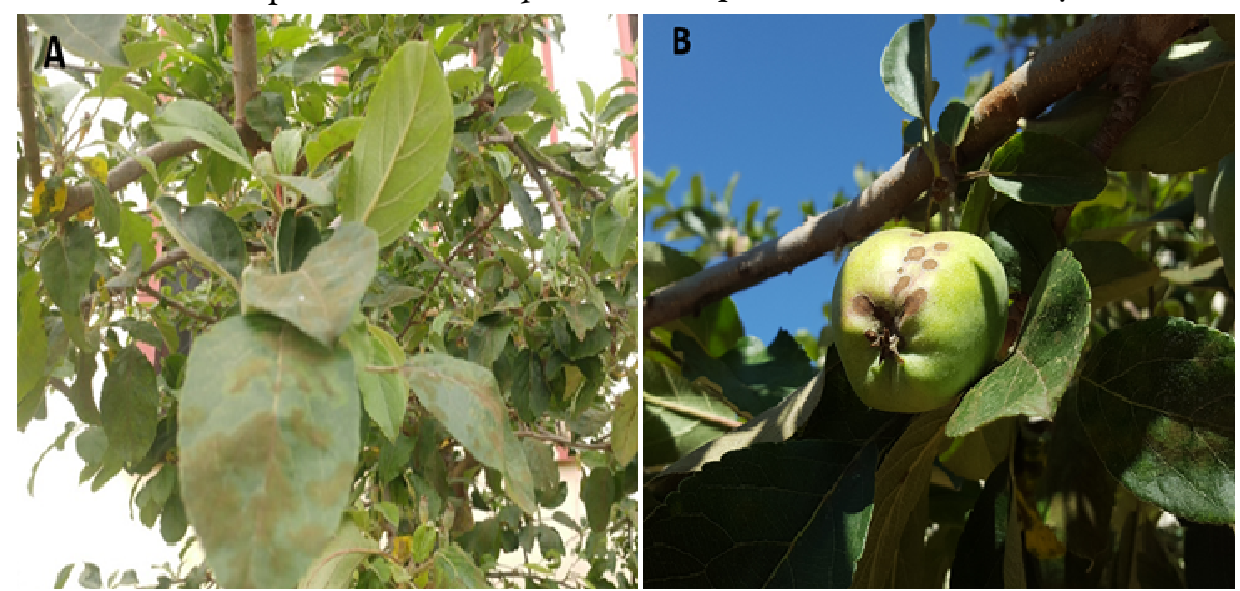

Fig. 1. Symptoms of $V$. inaequalis, causal agent of apple scab, on leaves (A) and fruit (B) of apple tree 


\section{Results}

Incidence and severity of apple scab in seven districts of the Sais region

Apple scab incidence and severity in the region was recorded in all the districts. The results from the survey showed that among the three cultivars, 'Golden Delicious' cultivar was relatively the most susceptible to apple scab with the mean incidence of $40.31 \%$, followed by 'Starking Delicious' (20.45\%) and 'Gala' (18.92\%) (Table 1). The highest mean of the incidence of apple scab appeared in Sidi El Makhfi community (40.91\%) of Ifrane province. In the two districts of Sefrou province, Ait Sbaa and Laanoucer, the incidence was $30.70 \%$ and $15.97 \%$ respectively. The least incidence was observed in Ait Naamane (14.10\%) of El Hajeb province (Fig. 2). There was a strong correlation between apple scab incidence and its severity in the surveyed region $(r=0.83)$. The grand mean of the disease incidence showed statistically a significant difference between the cultivars. Furthermore, there was a difference in the severity of the disease among the three cultivars. The lowest severity was observed in the orchards with 'Gala' cultivar (8.75\%). The severity of apple scab was highest in Ain Leuh of Ifrane province reaching the rate of $20.71 \%$ of the surface leaf area affected. The least severity was in Dayet Aoua and Laanoucer with the rate of $5.71 \%$. There were significant differences in the disease incidence and severity among the districts.

\section{In vitro sensitivity testing}

Sensitivity of Venturia inaequalis isolates to fungicides

After 12 days of incubation, percent inhibition of mycelial growth for each isolate was determined for each fungicide and concentration. A high variation in the sensitivity of each of the isolates of $V$. inaequalis was observed at all tested concentration levels. Difenoconazole had relatively different inhibitory effects on each of the two isolates. The inhibitory effect of this fungicide ranged from 9.43 to $70.94 \%$ for the isolate $\mathrm{ViEN}$ at the concentrations from $0.05 \mu \mathrm{g} / \mathrm{ml}$ to $10.00 \mu \mathrm{g} / \mathrm{ml}$ (Fig. 3A) and 13.42 to $85.00 \%$ for the isolate ViIF (Fig. 3B). According to the linear regression equations of the two isolates, the isolate $\mathrm{ViEN}$ from the untreated apple trees showed a lower sensitivity to difenoconazole and reflected a lower activity of this fungicide when compared to the isolate ViIF. There was a positive correlation between percent inhibition of the two isolates $(\mathrm{r}=0.927, P=0.023)$.

Trifloxystrobin had the greatest efficacy of the tested fungicides, inhibiting growth of the isolate $\mathrm{ViEN}$ from 13.57 to $91.44 \%$ (Fig. 3A) with concentrations from 0.05 $\mu \mathrm{g} / \mathrm{ml}$ to $10.00 \mu \mathrm{g} / \mathrm{ml}$ respectively. It also had the greatest effect on isolate ViIF, inhibiting growth from 10.10 to $92.63 \%$ (Fig. 3B) with concentrations from $0.05 \mu \mathrm{g} / \mathrm{ml}$ to $10.00 \mu \mathrm{g} / \mathrm{ml}$ respectively.

Table 1. Prevalence of apple scab in the seven districts of the Sais region

\begin{tabular}{|c|c|c|c|c|c|c|}
\hline \multirow{2}{*}{ Community } & \multicolumn{2}{|c|}{ Golden Delicious } & \multicolumn{2}{|c|}{ Gala } & \multicolumn{2}{|c|}{ Starking Delicious } \\
\hline & Incidence (\%) & $S(\%)$ & Incidence (\%) & $S(\%)$ & Incidence (\%) & $S(\%)$ \\
\hline Ain Leuh & 40.00 & 20.00 & 15.00 & 5.71 & 55.00 & 37.14 \\
\hline Ait Naamane & 35.33 & 24.00 & 1.11 & 1.90 & 0.00 & 0.00 \\
\hline Ait Sbaa & 42.00 & 20.86 & 31.90 & 18.37 & 26.67 & 14.86 \\
\hline Dayet Aoua & 35.83 & 8.57 & 3.33 & 3.81 & 0.00 & 0.00 \\
\hline Laanoucer & 19.74 & 6.59 & 14.44 & 4.76 & 8.00 & 4.57 \\
\hline Sidi El Makhfi & 55.00 & 32.50 & 33.33 & 12.38 & 32.50 & 22.86 \\
\hline Tigrigra & 54.29 & 25.71 & 33.33 & 14.29 & 20.95 & 17.14 \\
\hline Grand mean & $40.31^{\mathrm{a}}$ & $19.75^{b}$ & $18.92^{b}$ & $8.75^{\mathrm{c}}$ & $20.45^{b}$ & $13.80^{\mathrm{b}}$ \\
\hline
\end{tabular}

Percentages followed by the same letter do not differ significantly by Student $t$ test at $\mathrm{P}=0.05$

S: Percentage of affected leaf area

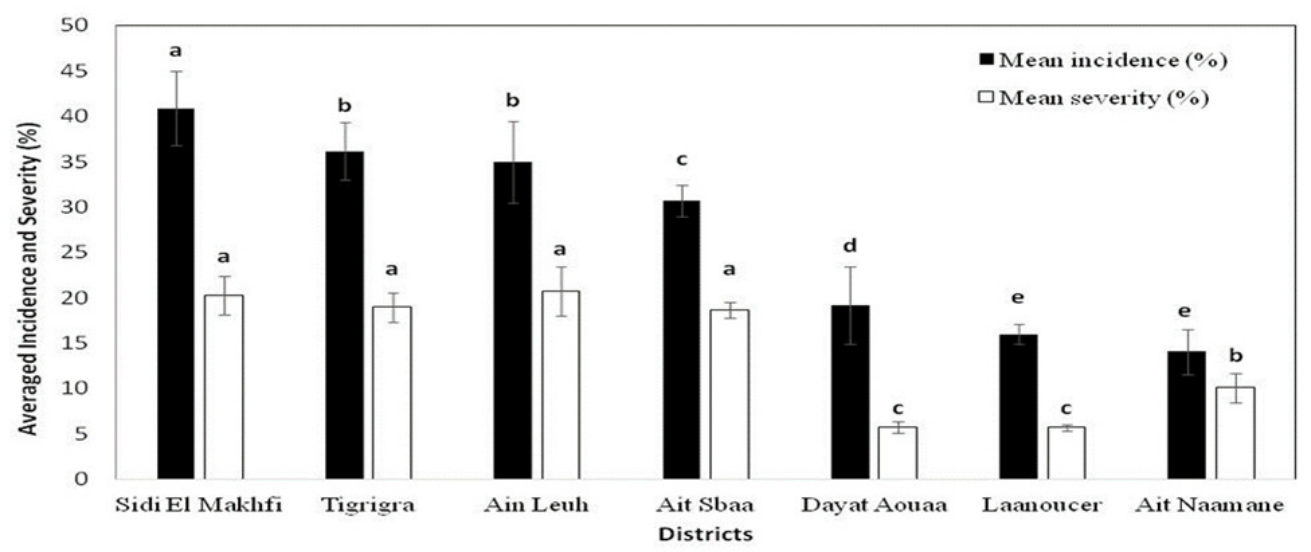

Fig. 2. Mean incidence and severity of apple scab in the different districts of the Sais region. Values marked with the same letter(s) are not statistically different $(\mathrm{P} \leq 0.05)$ 
The isolate ViIF was slightly less sensitive to trifloxystrobin than isolate ViEN, however there was a positive correlation between the two isolates $(\mathrm{r}=0.985, P=$ 0.002).

Thiophanate-methyl was the least effective at inhibiting mycelial growth of both isolates. At the same concentrations as the previously tested fungicides, growth of the isolate ViEN was inhibited between 9.43 and $70.61 \%$ (Fig. 3A). The growth of the isolate ViIF was inhibited between 11.75 and $59.05 \%$ (Fig. 3B). The lack of inhibition at the highest concentration of thiophanate-methyl reflected a loss of sensitivity of the isolate ViIF compared to ViEN. However, there was a positive correlation between the inhibitory effects of the two isolates $(\mathrm{r}=0.957, P=0.011)$.

Determination of $E C_{50}$ and resistance factor for the tested fungicides

After evaluating the mycelial growth of the pathogen, $V$. inaequalis, in each Petri dish, linear regression for each fungicide was established using fungicide concentrations and mycelial growth inhibition values (Fig. 3). For thiophanate-methyl, the regression equation was determined $\left(y=4.4045 x+17.593, R^{2}=0.869\right)$ and the fungicide concentration corresponding to $50 \%$ inhibition was calculated as $7.40 \mathrm{\mu g} / \mathrm{ml}$ for the isolate from the commercial apple orchard, ViIF. The same procedure was established for the other fungicides as well. EC 50 values were recorded for the isolates $\mathrm{ViEN}$ and ViIF were $5.84 \mathrm{\mu g} / \mathrm{ml}$ and $3.24 \mu \mathrm{g} / \mathrm{ml}$, and $2.33 \mu \mathrm{g} / \mathrm{ml}$ and $2.37 \mu \mathrm{g} / \mathrm{ml}$ for difenoconazole and trifloxystrobin, respectively (Table 2). The RF was calculated for the two isolates and the sensitivity of $V$. inaequalis isolate ViIF to difenoconazole was $(\mathrm{RF}=0.55)$, which was lower than the RF values found for thiophanate-methyl $(\mathrm{RF}=1.79)$ and trifloxystrobin $(\mathrm{RF}$ $=1.02$ ). Although trifloxystrobin had a lower RF value than thiophanate-methyl, a concentration of $10 \mu \mathrm{g} / \mathrm{ml}$ of trifloxystrobin was able to inhibit completely the mycelial growth of the isolates.

A three-way ANOVA showed that there was no significant difference in the inhibitory effects between the two Venturia isolates $(P>0.05)$. However, there were very high significant differences among treatments $(P=0.0001)$ and concentrations $(P=0.0000)$ on percent inhibition of $V$. inaequalis mycelial growth. There was no statistically significant interaction between treatments and concentrations in the inhibition of $V$. inaequalis mycelial growth $(P=0.0641)$ however, the interaction between Venturia isolates and treatments was highly significant $(\mathrm{P}=$ $0.0005)$ (Table 4). In

In vivo evaluation of fungicide efficacy on detached apple

Fungicide sensitivity was determined for the same concentration range on detached apple leaves after 28 days of incubation. Disease severity differed for each isolate based on the concentration and fungicide used. There were significant differences in disease severity on leaves between the active ingredients (treatments) in both the preventive
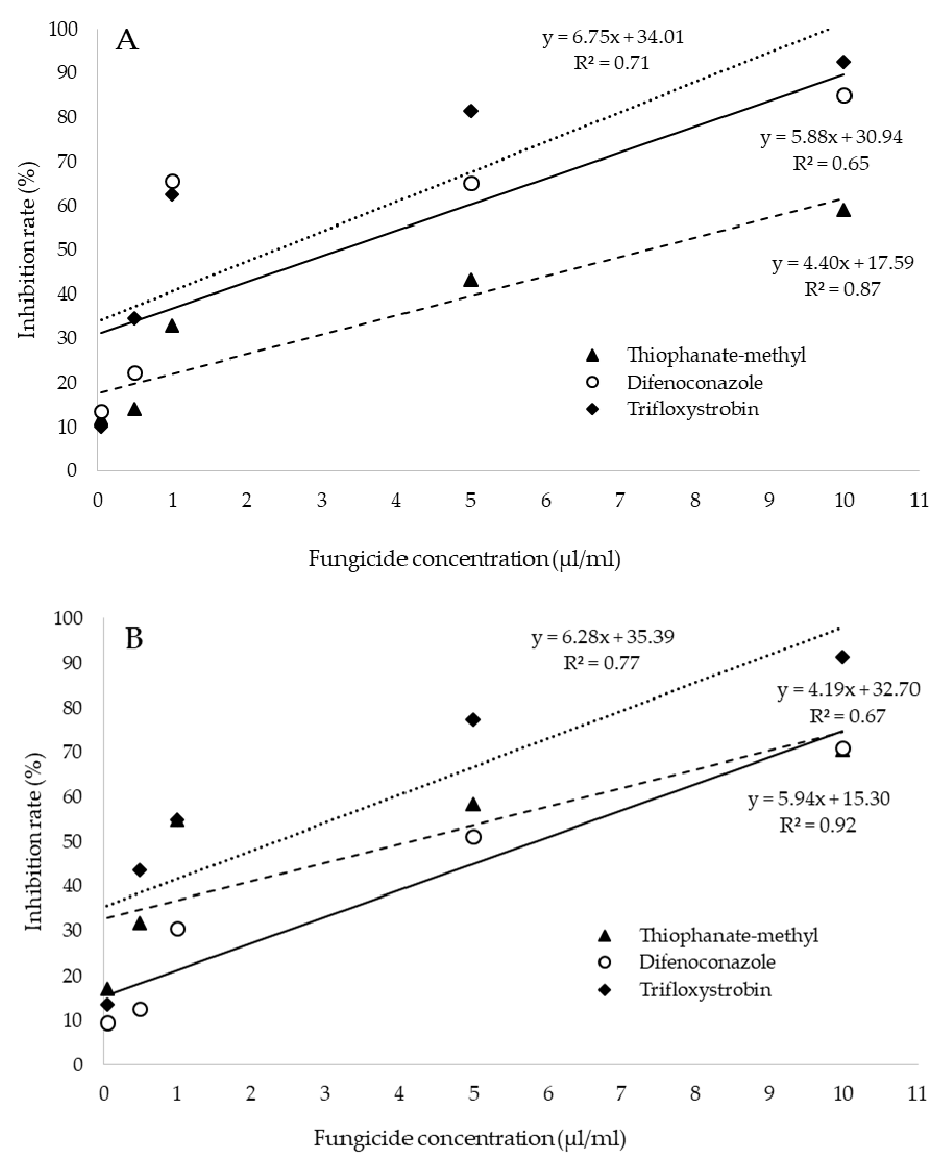

Fig. 3. Effect of three fungicides on the mycelial growth of the two isolates of $V$. inaequalis ViIF (A) and ViEN (B) 
254

Table 2. Sensitivity of $V$. inaequalis isolates to thiophanate-methyl, difenoconazole andTrifloxystrobin

\begin{tabular}{|c|c|c|c|}
\hline \multirow{2}{*}{ Active ingredient } & Isolate ViEN & Isolate VilF & \multirow[b]{2}{*}{$\mathrm{RF}$} \\
\hline & $\mathrm{EC}_{50}(\mu \mathrm{g} / \mathrm{ml})$ & $\mathrm{EC}_{50}(\mu \mathrm{g} / \mathrm{ml})$ & \\
\hline Thiophanate-methyl & 4.13 & 7.40 & 1.79 \\
\hline Difenoconazole & 5.84 & 3.24 & 0.55 \\
\hline Trifloxystrobin & 2.33 & 2.37 & 1.02 \\
\hline
\end{tabular}

Table 3. Averaged disease severity of the two isolates of $V$. inaequalis on detached apple leaves $(\mathrm{n}=4)$

\begin{tabular}{ccccccc}
\hline & \multicolumn{2}{c}{ Difenoconazole } & \multicolumn{2}{c}{ Thiophanate-methyl } & \multicolumn{2}{c}{ Trifloxystrobin } \\
\cline { 2 - 7 } & \multicolumn{1}{c}{ ViEN } & VilF & ViEN & VilF & ViEN & VilF \\
\hline 0.00 & $99.25 \pm 0.48^{\mathrm{a}}$ & $99.50 \pm 0.50^{\mathrm{a}}$ & $99.25 \pm 0.48^{\mathrm{a}}$ & $99.50 \pm 0.50^{\mathrm{a}}$ & $99.25 \pm 0.48^{\mathrm{a}}$ & $99.50 \pm 0.50^{\mathrm{a}}$ \\
0.05 & $78.57 \pm 9.22^{\mathrm{a}}$ & $85.72 \pm 14.26^{\mathrm{b}}$ & $99.38 \pm 0.63^{\mathrm{a}}$ & $71.43 \pm 13.04^{\mathrm{ab}}$ & $64.29 \pm 9.05^{\mathrm{bc}}$ & $52.50 \pm 3.37^{\mathrm{b}}$ \\
0.50 & $75.00 \pm 8.16^{\mathrm{b}}$ & $57.14 \pm 11.39^{\mathrm{b}}$ & $50.00 \pm 2.33^{\mathrm{b}}$ & $40.71 \pm 19.11^{\mathrm{b}}$ & $50.00 \pm 4.98^{\mathrm{c}}$ & $56.79 \pm 5.60^{\mathrm{b}}$ \\
1.00 & $85.72 \pm 8.25^{\mathrm{ab}}$ & $45.36 \pm 11.98^{\mathrm{b}}$ & $55.54 \pm 6.94^{\mathrm{b}}$ & $64.00 \pm 13.25^{\mathrm{ab}}$ & $64.29 \pm 5.08^{\mathrm{bc}}$ & $46.43 \pm 14.50^{\mathrm{b}}$ \\
5.00 & $68.75 \pm 4.75^{\mathrm{b}}$ & $50.00 \pm 2.91^{\mathrm{b}}$ & $40.71 \pm 7.77^{\mathrm{bc}}$ & $65.72 \pm 3.50^{\mathrm{ab}}$ & $67.86 \pm 4.86^{\mathrm{b}}$ & $42.86 \pm 16.45^{\mathrm{b}}$ \\
10.00 & $48.36 \pm 4.78^{\mathrm{c}}$ & $39.20 \pm 6.19^{\mathrm{b}}$ & $28.60 \pm 8.23^{\mathrm{c}}$ & $92.86 \pm 7.14^{\mathrm{a}}$ & $18.75 \pm 2.98^{\mathrm{d}}$ & $21.43 \pm 13.68^{\mathrm{b}}$ \\
LSD $_{0.05^{\mathrm{x}}}$ & 19.76 & 27.78 & 16.38 & 33.75 & 15.60 & 32.35 \\
0.00 & $99.25 \pm 0.48^{\mathrm{a}}$ & $99.50 \pm 0.50^{\mathrm{a}}$ & $99.25 \pm 0.48^{\mathrm{a}}$ & $99.50 \pm 0.50^{\mathrm{a}}$ & $99.25 \pm 0.48^{\mathrm{a}}$ & $99.50 \pm 0.50^{\mathrm{a}}$ \\
0.05 & $51.43 \pm 18.03^{\mathrm{b}}$ & $92.86 \pm 4.13^{\mathrm{a}}$ & $68.50 \pm 8.21^{\mathrm{ab}}$ & $68.22 \pm 8.66^{\mathrm{a}}$ & $96.43 \pm 3.57^{\mathrm{a}}$ & $71.43 \pm 11.66^{\mathrm{ab}}$ \\
0.50 & $73.71 \pm 5.99^{\mathrm{ab}}$ & $70.53 \pm 15.18^{\mathrm{ab}}$ & $57.14 \pm 17.50^{\mathrm{b}}$ & $82.14 \pm 13.52^{\mathrm{a}}$ & $92.86 \pm 7.14^{\mathrm{a}}$ & $50.32 \pm 17.17^{\mathrm{b}}$ \\
1.00 & $78.57 \pm 4.12^{\mathrm{ab}}$ & $50.00 \pm 17.97^{\mathrm{b}}$ & $30.86 \pm 14.04^{\mathrm{b}}$ & $75.00 \pm 14.73^{\mathrm{a}}$ & $72.50 \pm 15.11^{\mathrm{ab}}$ & $10.71 \pm 10.72^{\mathrm{c}}$ \\
5.00 & $80.00 \pm 5.00^{\mathrm{ab}}$ & $75.00 \pm 8.99^{\mathrm{b}}$ & $53.93 \pm 18.90^{\mathrm{b}}$ & $96.43 \pm 3.57^{\mathrm{a}}$ & $50.25 \pm 6.75^{\mathrm{bc}}$ & $3.57 \pm 3.57^{\mathrm{c}}$ \\
10.00 & $75.00 \pm 16.88^{\mathrm{ab}}$ & $75.00 \pm 11.93^{\mathrm{ab}}$ & $62.25 \pm 6.25^{\mathrm{ab}}$ & $70.00 \pm 8.41^{\mathrm{a}}$ & $36.00 \pm 10.34^{\mathrm{c}}$ & $3.60 \pm 3.60^{\mathrm{c}}$ \\
LSD $_{0.05^{\mathrm{y}}}$ & 31.82 & 34.18 & 37.72 & 28.66 & 25.59 & 28.99 \\
\hline
\end{tabular}

Means followed by the same letter in the same column are not significantly different according to Duncan's multiple range test $(P=0.05)$. Least significant difference (LSD) test at $P=0.05$ of mean disease severity using ${ }^{x}$ preventive method and ${ }^{y}$ curative method

Table 4. Analysis of variance for the effects of Venturia isolates, fungicide treatments and concentrations on inhibition rate of mycelial growth and mean severity of detached leaves

\begin{tabular}{|c|c|c|c|c|}
\hline Parameter and source of variation & $\mathrm{df}$ & Mean square & F value & $P$ \\
\hline \multicolumn{5}{|l|}{ 1. In vitro sensitivity test $(\mathrm{n}=4)$} \\
\hline \multicolumn{5}{|l|}{ Dependent variable: inhibition rate (\%) } \\
\hline Venturia isolate & 1 & 1.233 & 0.033 & 0.8583 \\
\hline Treatment & 2 & 802.042 & 21.657 & 0.0001 \\
\hline Concentration & 4 & 4264.008 & 115.138 & 0.0000 \\
\hline Venturia isolate $\times$ Treatment & 2 & 556.077 & 15.015 & 0.0005 \\
\hline Treatment $\times$ Concentration & 8 & 97.252 & 2.626 & 0.0641 \\
\hline Error & 119 & 37.034 & & \\
\hline \multicolumn{5}{|l|}{ 2. In vivo sensitivity test } \\
\hline \multicolumn{5}{|l|}{ Dependent variable: mean severity (\%) } \\
\hline \multicolumn{5}{|l|}{ x. Preventive method $(n=4)$} \\
\hline Venturia isolate & 1 & 684.870 & 1.460 & 0.2293 \\
\hline Treatment & 2 & 2692.867 & 5.742 & 0.0042 \\
\hline Concentration & 4 & 3200.164 & 6.824 & 0.0001 \\
\hline Error & 119 & 468.984 & & \\
\hline \multicolumn{5}{|l|}{ y. Curative method $(n=4)$} \\
\hline Venturia isolate & 1 & 889.523 & 1.073 & 0.3024 \\
\hline Treatment & 2 & 5968.732 & 7.199 & 0.0011 \\
\hline Concentration & 4 & 2415.540 & 2.913 & 0.0243 \\
\hline Error & 119 & 829.130 & & \\
\hline
\end{tabular}

and curative treatments (Table 4). With the curative treatment, specifically, disease severity on leaves treated with trifloxystrobin was much lower than that of the other active ingredients at a concentration of $10 \mu \mathrm{g} / \mathrm{ml}$ (Table 3). Mean disease severity of the control $(0.00 \mu \mathrm{g} / \mathrm{ml})$ of isolate ViEN from untreated apple trees $(99.25 \%)$ was slightly greater than that of isolate ViIF from the commercial apple orchard (99.50\%).
With the preventive treatment, the lowest disease severity was observed on leaves treated with trifloxystrobin. Disease severity ranged from 18.75 to $64.29 \%$ and 21.43 to $52.50 \%$, for the leaves inoculated with isolates $\mathrm{ViEN}$ and ViIF, respectively. The fungicide resulted in a greater reduction of disease severity on isolate ViIF with the curative treatment, with a range from 3.57 to $71.43 \%$. Moreover, disease severity was lower on leaves inoculated 
with isolate ViEN collected from untreated apple trees with the curative treatment (Table 3). The isolate ViIF was more sensitive to trifloxystrobin compared to the other fungicides in both the preventative and curative treatments.

With thiophanate-methyl, the variation in disease severity in the two treatments was clearly observed. With the preventive treatments, disease severity ranged from 28.60 to $99.38 \%$ and from 40.71 to $92.86 \%$, for the isolates ViEN and ViIF respectively. With the curative treatments, although disease severity was relatively higher than that of the preventive treatments, there was no significant difference between the mean of the two treatments. Leaves inoculated with the isolate ViIF had disease severity ranging from 36.00 to $96.43 \%$.

In the case of detached leaves treated with difenoconazole, mean disease severity recorded by the preventive treatments ranged from 48.36 to $85.72 \%$, and from 39.20 to $85.72 \%$, for the isolates ViEN and ViIF, respectively. The lowest disease severity was recorded from leaves treated with the highest concentration of fungicide. With the curative treatments, disease severity was between 51.43 and $80.00 \%$, and 50.00 and $92.86 \%$ for ViEN and ViIF, respectively.

In order to determine the efficacy of the fungicide treatment at a concentration of $10 \mu \mathrm{g} / \mathrm{ml}$, we had to consider the severity of the control $(0.00 \mu \mathrm{g} / \mathrm{ml})$ and the corresponding severity at a concentration of $10 \mu \mathrm{g} / \mathrm{ml}$ for each fungicide and for each isolate from the commercial orchard. Trifloxystrobin had the highest efficacy, $78.46 \%$ and $96.38 \%$, based on the preventive and curative treatments, respectively. Conversely, thiophanate-methyl was the least effective. Its efficacy was $6.67 \%$ for the preventive treatments and $29.65 \%$ for the curative treatments. In the case of difenoconazole, its efficacy was greater when used preventatively $(60.60 \%)$ compared to when it was used as a curative treatment (24.62\%).

According to the analysis of variance (ANOVA) of the sensitivity of $V$. inaequalis on detached leaves to fungicide application (Table 4), there were no significant differences between the two isolates in mean severity in either of the curative or preventive treatments. Fungicides applied as a curative treatment $(P=0.0011)$ showed higher significant effects than in preventive treatments $(P=0.0042)$ on mean disease severity. In other words, efficacy of fungicide treatments was significantly higher when used preventively compared to curatively. However, the effect of concentrations on mean disease severity on detached leaves was very highly significant in both the preventive $(P=$ $0.0001)$ and curative treatments $(P=0.0243)$.

\section{Discussion}

The susceptibility of apple cultivars to apple scab and sensitivity of $V$. inaequalis isolates to fungicides were demonstrated for the first time in Morocco. In this study, the comparison of fungicide efficacy used an isolate (ViIF) collected from a commercial apple orchard located in Ifrane province and another isolate (ViEN) from untreated apple trees in the National School of Agriculture of Meknes. After several microscopic observations, the spores were bicellular and asymmetrical. Thus, average size of the ascospores was approximately $15 \mu \mathrm{m}$. According to Vaillancourt and
Hartman (2000), the length of the ascospores varies between 12 and $15 \mu \mathrm{m}$, and the color is yellowish-green or brownish.

Disease survey. The visual method adopted in this study was carefully established in order to have a degree of accuracy as the more elaborate research method. Thus, Croxall et al. (1952) attest that the visual method of evaluation of apple scab infection gives a reliable result. In determining relative cultivar susceptibility, Biggs et al. (2010) fix a minimum of $10 \%$ scab leaf infection incidence on the cultivar. In this regard, all the three cultivars proved to be susceptible to apple scab. The susceptibility of the three cultivars to apple scab is known worldwide (Jha et al., 2010).

Knowledge on disease threshold, although not easily implemented, will help farmers confirm the efficacy of fungicide sprays. Visual monitoring of 20-50 trees per orchard of apple scab from green tip to fruit maturity stage will help reduce costs and fungicide inputs. The need for fungicide sprays during the summer is based on monitoring leaf scab incidence and using a threshold of 0.5 or $1.0 \%$ leaf scabbed (Carisse et al., 2009; Carisse and Jobin, 2012). A threshold of $7 \%$ scab incidence on developing fruit was proposed by Turechek and Wilcox (2005).

In vitro sensitivity testing. Efficacy of difenoconazole was lower on the isolate collected from untreated apple trees, ViEN, than the isolate collected from the commercial apple orchard, ViIF. The isolates insensitivity to the fungicides could be the result of several factors. For instance, $\mathrm{EC}_{50}$ values for difenoconazole were $5.84 \mu \mathrm{g} / \mathrm{ml}$ and $3.40 \mu \mathrm{g} / \mathrm{ml}$ for the isolates ViEN and ViIF, respectively (Table 2). At the same fungicide concentration range, Jobin and Carisse (2007) obtained a mean $\mathrm{EC}_{50}$ of $3.079 \mu \mathrm{g} / \mathrm{ml}$ for DMIs of the isolates obtained from commercial orchards. Similar results were recorded by Kunz et al. (1997) having obtained $\mathrm{EC}_{50}$ and RF values of $5.4 \mu \mathrm{g} / \mathrm{ml}$ and 59 , respectively. Conversely, these values were greater than the ones reported by Villani et al. (2015) and Fiaccadori, (2017) who reported baseline $\mathrm{EC}_{50}$ values of 0.0075 and $0.002 \mu \mathrm{g} / \mathrm{ml}$, respectively, and suggested that several isolates in the population were already insensitive to difenoconazole. The resistance factor obtained in our study was less than one. This showed that even though the $\mathrm{EC}_{50}$ values were highly influenced by the concentration range, the isolate from the commercial orchard was not very sensitive to the active ingredient. RF values documented by Mondino et al. (2015) were greater than five and with an $\mathrm{EC}_{50}$ value of $2.38 \mu \mathrm{g} / \mathrm{ml}$ under in vitro conditions.

The inhibitory effect of thiophanate-methyl was lowest compared to the other active ingredients. According to Quello et al. (2010), $V$. inaequalis isolates that can grow rapidly in $5 \mu \mathrm{g} / \mathrm{ml}$ of thiophanate methyl are classified as moderately resistant. Both of the tested isolates ViEN and ViIF, grew at this concentration. Even though the two isolates expressed sensitivity to trifloxystrobin, $\mathrm{EC}_{50}$ values were greater than $2 \mu \mathrm{g} / \mathrm{ml}$ Küng Färber $e t$ al. (2002) and Stević et al. (2015) obtained $\mathrm{EC}_{50}$ values less than $1 \mu \mathrm{g} / \mathrm{ml}$. According to Fiaccadori et al. (2011), isolates with $\mathrm{EC}_{50}$ values greater than $2 \mu \mathrm{g} / \mathrm{ml}$ and possessing the G143A substitution are considered resistant to trifloxystrobin. 
256

Resistance or sensitivity of $V$. inaequalis to trifloxystrobin has yet to be confirmed in in Morocco.

In vivo sensitivity tests. Trifloxystrobin at a concentration of $10 \mu \mathrm{g} / \mathrm{ml}$ showed satisfactory efficacy in controlling disease severity for both preventive and curative treatments for both isolates of $V$. inaequalis. With a concentration of $10 \mu \mathrm{g} / \mathrm{ml}$, the fungicide effectively reduced disease severity by 78.46 and $96.38 \%$ using the preventive and curative treatments, respectively. Comparatively, Stević et al. (2015) reported disease severity reduction of $31.0 \%$ when trifloxystrobin was applied at a concentration of $50 \mu \mathrm{g} / \mathrm{ml}$.

At a concentration of $10 \mu \mathrm{g} / \mathrm{ml}$, difenoconazole reduced disease severity of isolate ViIF by $60.60 \%$ with the preventive treatment and $29.65 \%$ with the curative treatment. The reduction in disease severity was greater than what was reported by Stević et al. (2010) who recorded a negligible a reduction in disease severity of $8.6 \%$ at a concentration of $30 \mu \mathrm{g} / \mathrm{ml}$. The obtained results concur with the findings of (Köller et al., 1997; Kunz et al., 1997).

Inadequate disease reduction (6.67 and $29.65 \%$, with preventive and curative treatments, respectively), was obtained when thiophanate methyl was used at a concentration of $10 \mu \mathrm{g} / \mathrm{ml}$ against ViIF (Table 3). This $\mathrm{MBC}$ fungicide was associated with high disease severity rates on both isolates at all concentrations tested.

The results presented above may not reflect the efficacy of fungicides under field conditions. This is supported by the fact that fungicide application during the in vivo tests was conducted $2 \mathrm{~h}$ before inoculation (preventive treatment) and after inoculation (curative treatment) with $1 \times 10^{5}$ spores $/ \mathrm{ml}$ applied to each of the detached leaves. The tested concentrations used in this study differ from recommended doses used in apple orchards. For instance, a dose of $15 \mathrm{ml} / \mathrm{hl}$ (150 ppm) of difenoconazole is recommended in field conditions (ONSSA, 2017). Optimal conditions for fungicide efficacy rarely occur under field conditions.

\section{Conclusions}

Disease survey showed the susceptibility of the three cultivars evaluated. In laboratory tests, there were no significant differences in fungicide sensitivity or mean disease severity between the two isolates of $V$. inaequalis. However, disease severity was significantly different among the fungicide treatments in both the preventive and curative treatments. The results presented are not quite representative of apple producing orchards as a limited number of isolates were used in this study. Furthermore, the results do not reflect the efficacy of fungicides under field conditions. For future research, we recommend using a larger number of isolates from various apple orchards. Contact fungicides should be tested in order to make comparisons with systemic fungicides on their efficacy against $V$. inaequalis. In addition, specific situations should be analyzed in detail to better understand the local response of $V$. inaequalis isolates to fungicides used to control the disease. Baseline sensitivity and molecular identification of races of $V$. inaequalis in Moroccan apple orchards will be of paramount importance.

\section{Acknowledgements}

The authors express their gratitude to the Phytopathology Unit of the Department of Plant Protection and Environment (Ecole Nationale d'Agriculture de Meknes, Morocco) for the financial support of this work.

\section{Conflicts of interest}

The authors declare no conflict of interest and the funders have no role in the design of the study; in the collection, analysis, or interpretation of data; in the writing of the manuscript, or in the decision to publish the results.

\section{References}

Abbott WS (1925). A method of computing the effectiveness of an insecticide.Journal ofEconomic Entomology 18(2):265-267.

Belete T, Boyraz N (2017). Critical review on apple scab (Venturia inaequalis) biology, epidemiology, economic importance, management and defense mechanisms to the causal agent. Journal of Plant Physiology and Pathology 5(2):2.

BelfantiE, Silfverberg-Dilworth E, TartariniS, Patocchi A, Barbieri M,ZhuJ, ... Sansavini S (2004). The HcrVf2 gene from a wild apple confers scab resistance to a transgenic cultivated variety. Proceedings of the National Academy of Sciences 101(3):886-890.

Biggs AR, Sundin GW, Rosenberger DA, Yoder KS, Sutton TB (2010). Relative susceptibility of selected apple cultivars to apple scab caused by Venturia inaequalis. Plant Health Progress 11(1):20.

Bolton MD, Rivera V, Secor G (2013). Identification of the G143A mutation associated with QoI resistance in Cercospora beticola field isolates from Michigan, United States. Pest Management Science 69(1):35-39.

Bowen JK, Mesarich CH, Bus VG, Beresford RM, Plummer KM, Templeton MD (2011). Venturia inaequalis: the causal agent of apple scab. Molecular Plant Pathology 12(2):105-122.

Carisse O, Jobin T (2012). Managing summer apple scab epidemics using leaf scab incidence threshold values for fungicide sprays. Crop Protection 35:36-40.

Carisse O, Meloche C, Boivin G, Jobin T (2009). Action thresholds for summer fungicide sprays and sequential classification of apple scab incidence. Plant Disease 93(5):490-498.

Chapman KS, Sundin GW, Beckerman JL (2011). Identification of resistance to multiple fungicides in field populations of Venturia inaequalis. Plant Disease 95(8):921-926.

Croxall H, Gwynne D, Jenkins J (1952). The raped assessment of apple scab on leaves. Plant Pathology 1(2):39-41.

Fiaccadori R (2017). Researches on methodologies to verify reduced sensitivities of Venturia inaequalis in field to difenoconazole and first indications of a survey in Italy. American Journal of Plant Sciences 8(09):2056.

Fiaccadori R, Cicognani E, Alberoni G, Collina M, Brunelli A (2011). Sensitivity to strobilurin fungicides of Italian Venturia inaequalis 
populations with different origin and scab control. Pest Management Science 67(5):535-540.

Fishel FM (2005). Pesticide toxicity profile: Triazole pesticides. University of Florida, IFAS extension. PI68.

Jha G, Thakur K, Thakur P (2010). The Venturia apple pathosystem: pathogenicity mechanisms and plant defense responses. BioMed Research International 2009.

Jobin T, Carisse O (2007). Incidence of myclobutanil-and kresoxim-methylinsensitive isolates of Venturia inaequalis in Quebec orchards. Plant Disease 91(10):1351-1358.

Khajuria Y, Kaul S, Dhar M (2012). Molecular characterization of Venturia inaequalis causing apple scab in Kashmir. Open Access Scientific Reports 1:339.

Khajuria YP, Kaul S, Wani AA, Dhar MK (2018). Genetics of resistance in apple against Venturia inaequalis (Wint.) Cke. Tree Genetics \& Genomes 14(2):16.

Köller W, Parker D, Turechek W, Avila-Adame C, Cronshaw K (2004). A two-phase resistance response of Venturia inaequalis populations to the QoI fungicides kresoxim-methyl and trifloxystrobin. Plant Disease 88(5):537-544.

Köller W, Wilcox W, Barnard J, Jones A, Braun P (1997). Detection and quantification of resistance of Venturia inaequalis populations to sterol demethylation inhibitors. Phytopathology 87(2):184190.

Küng Färber RB, Chin KM, Leadbitter N (2002). Sensitivity of Venturia inaequalis to trifloxystrobin. Pest Management Science: formerly PesticideScience 58(3):261-267.

Kunz S, Deising H, Mendgen K (1997). Acquisition of resistance to sterol demethylation inhibitors by populations of Venturia inaequalis. Phytopathology 87(12):1272-1278.

Machardy WE (2000). Current status of IPM in apple orchards. Crop Protection 19(8-10):801-806.

Machardy WE, Gadoury DM, Gessler C (2001). Parasitic and biological fitness of Venturia inaequalis: relationship to disease management strategies. Plant Disease 85(10):1036-1051.

Madrpm (2014). Conjoncture de la filière pomme [Situation of appleproducing sector]. http:// www. agriculture. gov.ma/sites/ default/files/141022-note_veille_pommes-sl.pdf Accessed 1 March 2018.

Moinina A, Lahlali R, Maclean D, Boulif M (2018). Farmers' knowledge, perception and practices in apple pest management and climate change in the Fes-Meknes Region, Morocco. Horticulturae 4(4): 42.

Mondino P, Casanova L, Celio A, Bentancur O, Leoni C, Alaniz S (2015). Sensitivity of Venturia inaequalis to trifloxystrobin and difenoconazole in Uruguay.Journal of Phytopathology 163(1):1-10.
Nicholson R, Van ScoyocS, KucJ, WilliamsE (1973). Response of detached apple leaves to Venturia inaequalis. Phytopathology.

Onssa (2017). Index Phytosanitaire Maroc [Phytosanitary Index of Morocco]. http://eservice.onssa.gov.ma/IndPesticide.aspx. Accessed 5 March 2018.

Oukabli A (2004). Le pommier: une culture de terroir en zones d'altitude [The apple: Origin-linked crop with higher altitudes]. https://www.agrimaroc.net/bulletins/btta_115.pdf. Accessed 17 February 2018.

Pandey D, Tripathi N, Tripathi R, Dixit S (19820. Fungitoxic and phytotoxic properties of the essential oil of Hyptis suaveolens [Fungitoxische und phytotoxische Eigenschaften des ätherischen Öis von Hyptis suaveolens]. Zeitschrift für Pflanzenkrankheiten und Pflanzenschutz/Journal of Plant Diseases and Protection 344349.

Quello KL, Chapman KS, Beckerman JL (2010). In situ detection of benzimidazole resistance in field isolates of Venturia inaequalis in Indiana. Plant Disease 94(6):744750.

Stević M, Tamaš N, Miletić N, Vukša P (2015). Different toxicity of the strobilurin fungicides kresoxim-methyl and trifloxistrobin to Venturia inaequalis isolates from Serbia. Journal of Environmental Science and Health, Part B 50(9):633-637.

Stević M, Vukša P, Elezović I (2010). Resistance of Venturia inaequalis to demethylation inhibiting (DMI) fungicides. Žemdirbyste - Agriculture 65-72.

Turechek WW (2004). Apple diseases and their management: Diseases of fruits and vegetables. Diagnosis and management. (1st edtn), Kluwer Academic Publishers, Dordrecht. In: Naqvi SaMH (Ed). Diseases of Fruits and Vegetables, Volume I: Diagnosis and Management. Dordrecht: SpringerNetherlands pp 1-108.

Turechek WW, Wilcox WF (2005). Evaluating predictors of apple scab with receiver operating characteristic curve analysis. Phytopathology 95(6):679-691.

Vaillancourt L, Hartman J (2000). Apple scab. The Plant Health Instructor. doi: 10.1094/PHI-I-2000-1005-01.

Villani SM, Biggs AR, Cooley DR, Raes JJ, Cox KD (2015). Prevalence of myclobutanil resistance and difenoconazole insensitivity in populations of Venturia inaequalis. Plant Disease 99(11):1526-1536.

Zhou Y,XuJ,Zhu Y,Duan Y,Zhou M(2016). Mechanism of action of the benzimidazole fungicide on Fusarium graminearum: interfering with polymerization of monomeric tubulin but not polymerized microtubule. Phytopathology 106(8):807-813. 